\title{
Sport, Genetics and the 'Natural Athlete': The Resurgence of Racial Science
}

\section{BRETT ST LOUIS}

Scientism is essentially based . . . on two postulates: integral determinism and the subordination of ethics to science. (Todorov, 1993: 114)

\section{Abstract}

As Western societies become increasingly multi-ethnic and states broadly embrace the ensuing diversity, even if only as a rhetorical ideal, racial and ethnic difference is an ever more sensitive and socially significant issue instead of a benign form of individual and group categorization. Indeed, many concerns over the social effects of racial and ethnic difference, for example the contemporary anxieties over refugees and asylum seekers, are articulated in cultural and/or economic terms - such as panics about 'economic migrants' - that deliberately avoid an explicit focus on race and/or ethnicity. Additionally, invidious under-standings of ethnic and racial difference are mutating into more palatable and imperceptible cultural forms that are disseminated through an expanded info-tainment sphere (Gilroy, 2000). The broader implications of these shifts, which necessitate the analysis of sport as an important cultural forum for the descrip-tion and explanation of racial difference, inform the point of departure for this article.

The body, specifically through the interpretation of phenotypical appearances, has long been an important resource for the formation of racist inferences. Placing this centrality of the body to racist ideals alongside the contemporary emergence of more implicit and subtle forms of racism based on the idea of insur-mountable cultural difference, sport is now more than ever a valuable and accept-able site for the representation and demonstration of embodied racial difference. James Monaco's (2000) description of Christian Metz's semiotics of .Im, which usefully describes the process by which a particular filmic sign or image reveals its own meaning without recourse to an interpretive semiotic process as a short-circuit sign, is particularly instructive here. The short-circuit sign in .Im collapses the distinction between signifier and signified and is an extremely powerful visual image that appears to best represent (social) reality by dispensing with the distinc-tion between primary and secondary orders of communication - an image or sound (signifiers) and its meaning (signifieds). This conflation of image and meaning where signifier and signified 'are nearly the same: what you see is what you get' (Monaco, 2000: 420) is potentially dangerous when applied to the under-standing of sporting performance because it provides a basis for the description of pathological embodied racial characteristics. The signification of racial group characteristics within modern sports continues to reflect the embodied formation of race evident within much Enlightenment and post-Enlightenment social thought and 19th-century racial science that mobilized notions of phenotypical difference as a means to reinforce European civilizational, cultural and national superiority. Whether it is the reification of a fundamental African-American athletic prowess (Hoberman, 1997), the archetypal tactical 
Published as: St Louis, Brett. 2003. Sport, genetics and the 'natural athlete': The resurgence of racial science. Body \& Society, 9(2), pp. 75-95.

ingenuity of white athletes (Burfoot, 1999), or the naturalistic mythology attached to Kenyan distance runners (Bale, 1999; Maguire, 1999), sport can be used to provide the short-circuit signs that reinforce embodied racial pathologies.

It is worth noting that such reified, archetypal and mythologized represen-tations are not simply benign pathologies that confirm, and remain at, common-sense levels of social explanation. Within the short-circuit sign, the visual image of sporting performance is both its symbol and its meaning, which is exempt from the semiotic slippage and subsequent sliding signification faced by the polysemous word. Therefore, an image of an athlete running means that an athlete is running and, situated within a guiding racial ontological matrix, the success or failure of their individual performance might be extended to symbolize the char-acter and ability of the particular racial group to which they belong. Surpassing the limited salience of popular racial pathologies as scientific forms of expla-nation, this conflation of image and meaning has been reworked as a symbolic representation of visual and biological truth that forms the basis for many discussions of the causal link between racial genetic inheritance and athletic achievement.

In this sense the sporting successes of black athletes is taken as raising the question, if not also providing the a priori evidence, of an innate racial ability or genetic advantage. Why, asks Amby Burfoot (1999), is sporting success and failure racially distributed given the theoretically level playing field of sports? Furthermore, if running is a universal activity, undertaken globally without the need for extensive resources such as expensive coaching, equipment or facilities - and is a perfect scientific 'laboratory' for the exploration of physical and performance differences between racial groups, why is the 'obvious' question of racialized sporting (dis)advantage assiduously avoided?

This article engages responses to this question provided within recent discus-sions of the relationship between race, the body and sport that suggest that the propensity for athletic ability is racially distributed. I argue that the notion of the racial basis of athletic ability strategically employs genetic science in order to support erroneous understandings of racial physicality and dismiss the irrational 'politically correct' dogmas of social constructionism. The significance of the use of genetic science is discussed both in terms of the analytical inflation of scientific truth claims within the racial athleticism paradigm and the social authority of science that restricts ethical debate by limiting the scope of critiques within a correct/incorrect science problematic. This article suggests that formal scientific analysis and its 'biocultural' concession to the significant social and cultural formative aspects of racial athletic ability are respectively ' scientific represen-tations' of enduring racial myths and a diversionary rhetorical strategy. As a corrective I argue that such objective scientific analyses of the racial distribution of athletic ability depend on the continual rei.cation of racial biological heredity within a social and cultural hierarchy that is analogous with the standard ideas expressed in the longer tradition of racial science. 
Published as: St Louis, Brett. 2003. Sport, genetics and the 'natural athlete': The resurgence of racial science. Body \& Society, 9(2), pp. 75-95.

\section{Sport, Genetics and Racial Taxonomy}

The publication of Richard Herrnstein and Charles Murray's The Bell Curve (1996) signalled an important public moment in the race and IQ debate; simi-larly, recent discussions of the links between race and athletic ability over the past 10 years exemplify new forms of racism that combine scientific and cultural frameworks. These debates, largely prevalent in North America as a result of a longer concern with the relationship between race and sport (Dyreson, 1989), have been conducted within special issues of journals and magazines,1 as well as significant contributions in single-authored books (Kohn, 1995; Hoberman, 1997). While opinion is sharply divided, Amby Burfoot's 1992 article 'White Men Can't Run' publicly advanced a controversial biological explanation for the 'obvious' and 'incontrovertible fact: black-skinned athletes are winning most races' (Burfoot, 1999: 62).2 This hypothesis is arguably most vigorously and extensively articulated in Jon Entine's provocatively entitled and controversial book, Taboo: Why Black Athletes Dominate Sports and Why We're Afraid to Talk About It (2000a).

Broadly put, the arguments for naturalized racial athletic aptitudes might be summarized as based upon an observable and measurable physical and physio-logical genetic advantage among black athletes. The suggestion is that physical specificities of body size and proportion, namely skeletal structure and muscula-ture, and the physiological facts of subcutaneous differences in the muscles, enzymes and cell structures, form the basis for black athletic advantage. However, it is crucial to note that these typologies are seen to emerge from a more funda-mental genetic basis: 'Preliminary research suggests that different phenotypes are at least partially encoded in the genes - conferring genotypic differences, which may result in an advantage in some sports' (Entine, 2000a: 18).

The establishment of genotype as a founding principle is crucial in attempting to secure a genealogy of heredity as an absolute producer of physical and physio-logical characteristics. Despite recognizing the attraction of using social, cultural, economic and historical markers as a means to explain racial sporting perform-ance, it has been argued that research pointing towards 'inherited fundamental metabolic racial differences' warns against completely rejecting a genetic theory of sporting ability (Bouchard, 1988: 107). Therefore, the assertion of a genotypic foundation (re)produced through heredity tilts the debate towards biological forms of explanation. The absolutism of genetic linearity questions the role of socialized phenotypical characteristics - derived from the articulation of genotype and environment - as the foundation for sporting advantage.

These racialized genotypes are posited as generating physiological character-istics that, in turn, facilitate specific physical capacities that emerge within sporting practices. Taking such practices as generally oriented towards either speed or endurance, sports scientists have observed a corresponding 'slow-twitch'/'fast-twitch' muscular duality of physiological capacity.3 Performance in sports predicated on speed is seen to depend on the distribution of 'fast-twitch' muscle fibres and anaerobic enzymes that are crucial to explosive physical capacity. Conversely, endurance is understood as dependent on the development of aerobic ability through the capacity to efficiently diffuse oxygen from the blood throughout 'slow-twitch' muscle fibres. Although the diverse and opposing physiological demands of speed and 
Published as: St Louis, Brett. 2003. Sport, genetics and the 'natural athlete': The resurgence of racial science. Body \& Society, 9(2), pp. 75-95.

endurance might appear to refute the argument for an archetype of black genetic sporting advantage, Burfoot and Entine combine the universality of race and the particularities of athletic performance within an evolutionary history of Africa. The disparate physical and physiological attributes required for speed and endurance are understood to have evolved throughout West and East Africa respectively out of a unified and 'original' African genotype. Therefore, the genetic basis of the capacity for speed and endurance within contemporary black sporting performance is intermedi-ately traceable to respective West or East African racial ancestry which, in turn, emerges from an originary 'African' gene pool that serves as the monogenesis of human genetic history.

The recognition that 'elite black athletes have a phenotypic advantage - a distinctive skeletal system and musculature, metabolic structures, and other characteristics forged over tens of thousands of years of evolution' (Entine, 2000a: 18) is not simply a disinterested scientific observation of sporting perform-ance. It is explicitly attached to a political position and the controversy surround-ing scientific debates on race has sometimes been understood as a result of an atmosphere charged with direct racism and 'unconscious' racist attitudes (Bouchard, 1988). Some commentators have been less measured in their assess-ment of the intellectual terrain and, for Burfoot and Entine, the contemporary orthodoxy of political correctness creates an intellectual climate of fear that disengages hard questions about the racialized nature of genetic sporting (dis)advantage: 'The shroud of silence results, of course, from our societal taboo against discussing racial differences' (Burfoot, 1999: 53). Furthermore, the academic conventions of socially constructed identities are seen to have created a vacuous relativism unable to describe, let alone explain, biological differences. Social constructionist arguments that question the efficacy of genetic racial differ-ence as a valid basis for social inquiry are dismissed as subjective and emotive ideological positions far removed from objective scientific insights. The assertion is that the (largely sociological and anthropological) rejection of biologically distinct racial groups obscures the indisputably racialized metaphysics of sporting performance.

The pivotal issue is whether innate biological racial differences can be discussed without explicit or implicit racism. Entine and Burfoot not only seem to think so, but they also suggest that the denial of race as an essential form of individual and group categorization and identification is problematic: 'Humans are truly diverse, biologically and culturally. Acknowledging our differences may approach a danger zone, but pretending that there are no slippery questions does not prevent them from being asked, if only under one's breath' (Entine, 2000b: 64). Therefore, political correctness is projected as an oppressive intellectual orthodoxy that ignores human curiosity and holds the ultimate social sanction in its ability to brand its opponents as racist. It circumscribes debate and silences the objectivity of genetic science that proves the common-sense knowledge right before our eyes in the short-circuit signs of sport.

\section{Race and the Limits of Science, or, the Science of Limits}

The vocational will to truth within the natural and physical sciences has been strenuously scrutinized and notable critiques have regarded the scientific process as one of verification and falsification (Popper, 1963: 215-50), which, instead of producing conclusive proof, acts as paradigmatic knowledge situated within and relative to distinct historical contexts (Kuhn, 1970). The broader limitations of absolute scientific truth claims 
Published as: St Louis, Brett. 2003. Sport, genetics and the 'natural athlete': The resurgence of racial science. Body \& Society, 9(2), pp. 75-95.

are conspicuous in the consistent use of disclaimers stipulating that the connection between race, genetics and sporting ability and performance are virtually or generally recognizable and that the data used might suggest certain conclusions or indicate a particular tendency (Bouchard, 1988; Boulay et al., 1988; Malina, 1988; Samson and Yerlès, 1988; Burfoot, 1999; Entine, 2000a). These linguistic disclaimers highlight the methodological issues and problems of using incoherent premises and an induc-tive approach as the basis for formulating a conclusive general proposition. In turn, this misguided theorization and conceptualization fuels an acute termino-logical imprecision that severely limits arguments for inherited racial genotypes, if not rendering them untenable.

The problematical reduction of sporting ability and performance to racial genotype is transparent in its presentation of definitive outcomes from general-ized observation and theorization. For example, the enthusiastic belief that the Human Genome Project 'will decipher all 100,000 human genes . . . and tell us more about ourselves than we are prepared to know, including, in all likelihood, why some people run faster than others' (Burfoot, 1999: 54) bases its argument on one strand of contested scientific opinion on the total number of genes within the human genome and their purported functions. The publication of rival drafts of the human genome sequence, which suggest that it comprises between 26,000 and 40,000 genes (International Human Genome Sequencing Consortium, 2001; Venter et al., 2001), severely tempers the meaning of the higher figure of 100,000 . The relatively small number of genes significantly challenges notions of human genetic determinism inasmuch as 'the much lower gene tally than anticipated ... indicates that human complexity does not arise solely from the number of genes' (Dennis et al., 2001: 813). Therefore, even though the notion that individual genes correspond to specific traits and characteristics remains unproven, the salutary point is that scientific information on, and knowledge about, the function of genes is neither definitive nor conclusive.

Analyses of black sporting success through racial taxonomies and the genetic heredity of athletic ability are further problematized by gender. If the scientific hypothesis of black sporting supremacy is able to assert the existence of heredi-tary genetic traits as accountable for the racial distribution of sporting ability, then we might easily expect to witness the dominance of black women as well as men. But, regarding women's athletic performance within the same 'perfect laboratory', why is this patently not the case? Why are women's Olympic 100 metres finals not all-black events? Why are we unable to trace the 'racial ancestry' of all the holders of women's world track running records to Africa?

In the face of these questions, Entine asserts that the sporting performance of men and of women is incomparable. He recognizes the initial social factors of particular gendered roles that blocked women's extensive participation in organ-ized and professional sports up until the mid-20th century. The symbolic positioning of men as sporting role models - and black men as racial representa-tives - restricted the opportunities for (black) women and this was exacerbated by the social expectation that they would ful.I 'feminine' domestic and social roles. However, accepting the significant post-Second World War advances by black women athletes, Entine recognizes the struggle between the natural and pharmaceutical sporting laboratories as the main explanatory factor for the differ-ing success levels of black men and women. He 
Published as: St Louis, Brett. 2003. Sport, genetics and the 'natural athlete': The resurgence of racial science. Body \& Society, 9(2), pp. 75-95.

suggests that the state-admin-istered performance-enhancing drug programmes of the former Eastern bloc countries drastically improved Eastern European women's performances and thus temporarily overcame the incontrovertible fact of black athletic supremacy. This remains unconvincing in many ways. Perhaps most importantly, if social factors such as opportunity and the synthetic interventions of drug use are able to significantly influence sporting performance then sport cannot be understood as a natural laboratory demonstrative of innate, natural athleticism that tran-scends the social variables of resource distribution.

The 'taboo' is thus recast as a mirage, and the well-documented sporting domi-nance of the 'black race' is reified through the narrow constituency of black men.4 However, the significant problems regarding the particular subject of black men and the general object of race are especially evident when we turn to the term 'black'. The terminological imprecision and confusion over the concept of race presents a major theoretical and political problem within discussions of the racial distribution of inherited genetic athletic ability. The numerous assertions of race as socially and culturally constructed not only profoundly disrupt notions of its biological essence (Benedict, 1935; Miles, 1989; Guillaumin, 1995), but also problematize the validity of its critical and common usage. Even Burfoot and Entine account for the question mark over the organic salience of race in quali-fying the retention of their commitment to scientism. Burfoot concedes that "the word "black" provides little information about any one person or any group. . . . West Africans and East Africans are both blacks, but in many physical ways they are more unlike each other than they are different from most whites' (1999: 59, emphasis in original). Similarly, Entine recognizes the contestation of race as a cohesive category. He describes it as a 'fuzzy concept' (2000a: 9, 110) in that phenotypes 'can be confusing markers of race' (2000a: 98), and notes significant social aspects of the formation and function of race.

Despite acknowledging the complexities of racial formation and difference, Entine assumes that race and racial ancestry are infinitely knowable and narrowly defined within separate and distinct categories. He then attempts to bring the blurred formation of race into sharp biological focus by referring to racialized athletic prowess as the result of genetic luck, 'cultural serendipity' and personal ambition. Situating racial genetic heredity within the framework of chance, he attempts to position himself against the progenitors of race science who located race within teleological histories of the spirit of human culture and civilization that established racial hierarchies of cultivated humanity and sub-human barbarism (Gobineau, 1966; Knox, 1996; Cuvier, 1997).

The conceptual coherence of basing a biological understanding of the physical characteristics and capacities of distinct races on inherited genetic materials distributed by 'chance' remains, at best, exceptionally weak. And, by invoking biological characteristics transmitted through heredity, this conceptualization depends on a strictly enclosed genealogy that, contradicted by its instrumental alignment with chance, is increasingly difficult to sustain. Indeed, some research on racial genetic inheritance and sporting performance recognizes that race is difficult to determine precisely when dependent on the concept of 'pure descent' (Samson and Yerlès, 1988: 114). Therefore, while Burfoot recognizes the facile equation of race to skin colour, yet continues to use it, Entine distinguishes between 'black Hispanic ballplayers' and 'players of mixed black and white heritage' (2000a: 22) without explicating his understanding of a 'black 
Published as: St Louis, Brett. 2003. Sport, genetics and the 'natural athlete': The resurgence of racial science. Body \& Society, 9(2), pp. 75-95.

race' and (a black Hispanic) racial ancestry as discrete and internally coherent forms. This conceptual confusion is compounded by tracing the ancestral origin of every male holder of world running records, including the individual members of relay teams, to East, West or North Africa (Entine, 2000a: 30). In this analysis, Entine equates ancestry to 'home country' and surreptitiously uses the 'one-drop rule' - whereby 'one drop' of 'black blood' in an individual irrevocably identifies their racial identity as 'black' - to assume a singular ancestral 'line' without mention or recognition of the ethnic plurality of ancestry and its effects on racial formation. The bankruptcy of this position is evident when, stripped of recourse to phenotypically simplified genealogical characterization, he identifies the 'racial ancestry' of the Brazilian middle-distance runner Joaquim Cruz as 'unclear' (2000a: 36).

While the effects of migratory patterns on racial ancestry profoundly disrupt the attempt at identifying the cohesive racial genealogies that lie at the heart of his project, Entine argues that, heretofore, racial mixing has not eradicated genetic difference and that genes are passed on whole within a selective group. 5 Even his qualified acceptance of the 'distant possibility' of the erosion of racial genetic differences represents a significant deviation from the orthodoxy of genetic science. The erroneous and disingenuous con.ation of genotypical variation and racial categorization pointed out within a range of key positions in popular science (Jones, 1994; Gould, 1997; Rose, 1997) is reiterated by the private project of Celera Genomics to map the human genome (Venter et al., 2001). Having deliberately selected DNA from .ve individuals of differing ethnicity, Celera was unable to match the anonymous genetic material to the individual donor on that basis. Its head Craig Venter then asserted that 'serious' genomic scholarship does not understand race as a scientific concept. 6 Accepting Barbara Culliton's asser-tion that race 'has no basis in science. The biologic concept of race is now believed to be untenable', 7 the adherents of genetically determined and distinct races might be regarded as outside the orthodoxy of the very scientific community that they draw on for legitimization and authority.

\section{Scientific Representations and Racial Mythology}

Despite the tenor of the arguments outlined above, I am not primarily concerned with the formal limitations and fallibility of science. Rather, in the remainder of this article I want to explore the sometimes obscured qualitative discourses within the edifice of scientific knowledge and discuss their operationalization within debates on race and sport. The convergence of the scientific and the discursive is evident in Entine's oscillation between social, cultural and biological forms of description and explanation that, despite accepting the problematic status of race, appears to settle on a foundational biologism and scientism. His recognition that the problematic conceptualization of race 'is compounded by the historical reality that theories about race have been frequently superficial and almost always reifective of a social agenda, whether unstated or unrecognized' (Entine, 2000a: 9) implies that apparently value-free claims of scientific analyses of race and sport ought to be exposed to social and ethical examination. 
Published as: St Louis, Brett. 2003. Sport, genetics and the 'natural athlete': The resurgence of racial science. Body \& Society, 9(2), pp. 75-95.

In the context of sport, when considering the signification of the (racialized) body the simple fact is that disinterested corporeal matter is fundamentally unin-teresting. Bone density and structure and the aerobic or anaerobic capacities of muscle fibres, are intrinsically meaningless until they are ascribed particular social values or become a receptacle for embodied experience and knowledge. 8 There-fore, the ability to run is meaningless outside a particular socialized experience and function which is further enhanced by the value attached to being able to run quickly over a specified distance. The perception of sport as a set of universalized physical activities endows it with intrinsic and naturalized properties that ignore the given and interested social contexts that the specific technical, aesthetic, temporal and spatial structures of sports as well as their particular rules and regu-lations emerged within (Blake, 1996). This contests the notion of sport as innocent 'play' and recasts it as developing specific bodily regimes that are charged with symbolic significance that animate a series of discourses including race. Therefore, despite suggesting that running and jumping are inherently natural activities and that track and field athletics represents a perfect laboratory, we are well reminded that specific sports are distinctive practices situated initially within a 'space of sports' and subsequently positioned within the broader 'social space' (Bourdieu, 1990), and that sport is a crucial site for the ideological (re)production of social orders (Brohm, 1978; Hargreaves, 1982, 1986; Bourdieu, 1992).

These theoretical insights are instructive for understanding the scientific analysis of the racialized sporting body and allow us to recognize the scientific analyses outlined above as scientific representations. These representations are significations of human material within a posited natural world that, as a result of the elevated social position occupied by science and its authoritative function as an instrument of power (Feyerabend, 1978), are legitimated through appeals to the foundational scientific tenet of disinterested objectivity. The methodo-logical errors of these residual representational and qualitative factors are astutely recognized by Ben Carrington and Ian McDonald: 'It seems that one of the basics of scientific statistical methodology - that all first year undergraduates know only too well - namely that correlation does not prove causation, is lost on many of those working within university sport science departments' (2001: 6). The production of sports scientists' research hypotheses and subjects, the chosen experimental and observational techniques, and methods of data analysis are inex-tricably linked to and informed by their subjective and qualitative prior under-standing of race (Fleming, 2001). This suggests that the correlation between race and athletic ability is not observed by a value-free scientific eye, but that pre-existing ideas about racial physical and moral capacities frame the very question and investigation of innate athleticism and athletic propensity.

The application of representational matrices to scientific analyses of racial sporting aptitude depend on the prior signification of materiality where the quali-tative discourses of black athletic performance are constructed and read as innate natural characteristics that exist prior to signification. This process and the extent of what is at stake here is chillingly clear in Burfoot's understanding of the corre-lation between race and basic physical aptitudes, motor skills and the propensity for technical development. He begins by noting that when 'pure explosive power - that is, sprinting and jumping - is required for excellence in a sport, blacks of West African heritage excel' (1999: 62). However, understanding the varied requirements of 
Published as: St Louis, Brett. 2003. Sport, genetics and the 'natural athlete': The resurgence of racial science. Body \& Society, 9(2), pp. 75-95.

different sports, he notes that as 'a sport moves away from speed and toward technique and other prerequisites, like eye-hand coordination, the more other racial groups find themselves on a level playing field' (1999: 62-3). Burfoot's conceptualization of the practical and symbolic formations of sport creates a critical distinction between the expression of the 'pure' body and bodily performance mediated by the mind. This distinction does not simply point to different modes of play, but produces racially ascribed ontological characteristics and cognitive abilities. Despite acknowledging the implicit marginalization of mental attributes in overemphasizing the physical abilities of black athletes (Burfoot, 1999: 53-4), this separation of 'explosive power' and 'technique' isolates the former as a primal physicality (synonymous with 'African ancestry') at least to some degree separated from the cognitive skills crucial for the understanding and execution of technique prevalent within other racial groups.

This distinction between the physical and cognitive realms of embodiment returns us to the familiar scenario of the racialized mind/body split that provided the basis for 19th-century racial science that grew out of earlier speculative racial geographies and anthropologies. The discourse of black hyper-physicality that Burfoot alludes to draws on the racial taxonomies that contrast the primal phys-icality and sensuality of black bodies, and their infantile minds, with the cultured sociability of white Europeans. This is evident in wideranging examples that include Hegel's (1975) conception of 'World History' and Locke's (1960) recog-nition of the 'spontaneous hand of nature' that distinguish between those Euro-peans who exercised reason to develop and improve their physical and social environment and the barbaric and uncultivated Others who, living as beasts in a state of nature, were unable to master their surroundings and merely collected from the land. There is a possible rejoinder here in that, as philosophical reflections, these positions are invariably speculative and imaginative representations of human groups and as such are inevitably un scientific. However, this line of defence remains problematic because the core metaphysical distinctions of these philosophical representations resurface within scientific representations, which in turn inform scientific analyses of race and sport, through the application of Darwin's 'law of compensation' that places intelligence and physicality in a zero-sum relationship (Hoberman, 1997; Fleming, 2001).

This racially ascribed paradigm where one is either physically capable or cognitively endowed is not simply a historical anomaly of philosophical and scientific knowledge but demonstrates particular racialized narratives that have mutated within our contemporary cultural vocabulary. The popular discussions of 'the meaning of black athletic achievement [that] have mobilized new scientific theories and timeworn myths in equal measure' (Gilroy, 2000: 256) are clearly evident in the evolution of sports science dogmas of distinct racial physio-logical and physical differences out of imaginative racial pathologies. The signa-ture of black primal physicality that John Hoberman (1997) recognizes as deeply embedded within American racial folklore has been transposed onto modern understandings of black athletic performance. These folkloric narratives that constructed black slaves as automatons and informed the representation of the 'buck' drew on the psychological ideas of black sensuality, exuberance, and instinctive impassivity allied to the physiological notions of significant anatomi-cal difference and hardiness. These popular representations assumed a sporting resonance, drawing on perceptions of a black racial propensity to endure pain, display quick reflexes and maintain a state of relaxation as well as extensive conjectures on physique including limb 
Published as: St Louis, Brett. 2003. Sport, genetics and the 'natural athlete': The resurgence of racial science. Body \& Society, 9(2), pp. 75-95.

length, bone density, enhanced muscula-ture, hyperextensibility, projecting heel bones and durable Achilles tendons. These physical, physiological and psychological stereotypes are clearly unified in the summation of Dean Cromwell, the head coach of the US Olympic team in the 1936 Berlin Olympics that included Jesse Owens:

... the Negro excels in the events he does because he is closer to the primitive than the white man. It was not long ago that his ability to sprint and jump was a life-and-death matter to him in the jungle. His muscles are pliable, and his easy-going disposition is a valuable aid to the mental and physical relaxation that a runner and jumper must have. (cited in Hoberman, 1997: 199)

As much as we might like to think that such crude pathologies are now simply historical incongruities, they are continually recycled in a range of examples including Roger Bannister's self-consciously ignorant curiosity over long-defunct notions of racial skeletal differences and climatic adaptation, and Burfoot's equation of Asians' lack of sporting success with 'their' diminished physical stature. However, most importantly, these representational fault-lines in the value-free façade of genetic science as the guardian of racial truth invite ethical scrutiny: is scientific logic impervious to and exempt from broader social responsibilities? And, given the inglorious history of racial science, can a science of race be recuperated in a way that eradicates the social centripetal forces that draw it towards the axes of superiority and inferiority?

\section{The Biocultural Third Way, or, The Naturalization of Culture}

It has long been argued that the participatory over-representation of certain racial groups within particular sports is the result of a socially constructed tradition whereby individuals gravitate towards certain sports and athletic events because of a desire to emulate role models within their ethnic group (Edwards, 1973; Cashmore, 1982). However, while accepting the social viability of this perspec-tive many commentators remain unconvinced of its singular explanatory salience in that it neither identifies nor explains the supposed intrinsic physical ability required for success. Therefore, the acceptance of significant social and cultural factors alongside the existence of physical and physiological factors has led some to revisit the sociobiology paradigm and argue for a 'biocultural approach' as the only feasible alternative to the unproductive polarities of sociological and anthropological constructionism and unrestrained biologism. Indeed, both Burfoot and Entine subscribe to this position and gesture towards the significance of social roles and processes of socialization within racial group sporting achievement as a crucial intangible that undiluted scientism cannot account for. Accepting that '[n]ature (the overall cultural environment) is just as important as biology (genetics)' (1999: 54), Burfoot acknowledges the efficacy of a biocultural approach that articulates biological and cultural factors. Similarly, Entine suggests that '[b]lack athletic success reflects bio-cultural factors' inasmuch as 'cultural conditions exaggerate the small but meaningful differences that led to the athletic edge' (2000a: 279, emphasis added). These biocultural factors are detailed further in his discussion of the ascetic regimes and aspirational values that work along-side the perceived genetically enhanced aerobic capacity of the Kalenjin 'tribe' that has produced most of Kenya's successful distance runners, and his assertion that genetics and the environment reinforce and reshape each other. 
Published as: St Louis, Brett. 2003. Sport, genetics and the 'natural athlete': The resurgence of racial science. Body \& Society, 9(2), pp. 75-95.

The retention of a basic notion of intrinsic biological differences between different racial groups creates a series of problems that prevent this biocultural third way from offering a progressive resolution of the constructionism/biolo-gism impasse. The statement that black athleticism reflects biocultural factors and exaggerates small biological differences foregrounds the biological factors and minimizes contributory cultural factors. Despite gesturing towards the significance of culture, the stubborn primacy of physical and physiological factors implicitly undermines the salience of an articulated biological-cultural approach. However, this meta-biologism is perhaps unsurprising when one considers the conceptual emergence of nature and culture and their relationship to race. The historical and conceptual entanglement of nature, culture and race is one of formative inconsistency and obscured premises that, in turn, raise significant doubts about the efficacy and utility of bioculturalism.

Peter Wade (1993) has usefully argued that the nature/culture binarism is firmly positioned within a 'productionist logic' where the slippage between race and culture consequently subsumes nature through the notion of 'phenotypical variation'. This suggests that even though phenotype is understood as an external indicator of the socially and culturally constructed form of race, it is taken for granted as 'an obvious objective fact when in fact it is a highly socially constructed one' (Wade, 1993: 21). This presents phenotypical variation as a universal and 'timeless concept' that provides a 'relatively culture-free biological base line' (Wade, 1993: 22) and grounds the neutrality of the disinterested analyst of the relationship between race, nature and culture. The very notion that biology and culture are separate entities that might be objectively articulated (and then tacitly disconnected) within a biocultural perspective on race ignores the extent and meaning of their intimate historical and conceptual entanglement.

Wade's discussion of the formation and deployment of phenotypical variation is important as a counter to the suggestion within sporting biocultural approaches that biology is simply a normative term referring to a set of disinterested prac-tices that describe and analyse objective phenomena. The blurred line between nature and culture suggests that the ideas and practices of biology are themselves social in formation and application. However, this conceptual imprecision of the biocultural third way generates broader social and ethical implications that are apparent in what Marshall Sahlins (1977) instructively recognizes as the 'folk dialectic of nature and culture'. Sahlins argues that nature and society have been co-dependent descriptive and explanatory forms within the emergence of Euro-American modernity where human characteristics have been understood as forged in nature while, simultaneously, human development and interaction are distinctively social.

The converse archetype within this folk dialectic is the 'noble savage' that informs the 'traditional' anthropological model of non-Western primitivism. The adaptation of these traditional anthropological models not only reifies settled tribal group formations as historically constant without reflecting their recent basis in regional political, social and economic networks and relations (Mac-Eachern, 2000) but, more importantly, demonstrates the deleterious aspects and ethical problems of bioculturalism. In distinguishing 
Published as: St Louis, Brett. 2003. Sport, genetics and the 'natural athlete': The resurgence of racial science. Body \& Society, 9(2), pp. 75-95.

between the social actor who has emerged from nature and the tribal primitive who remains firmly within nature, the manifestation of both sides of the folk dialectic within biocultural analyses of race and sporting performance contrasts the subjectivity of evolved consciousness with the objectification of racialized curiosities. This fallacious analysis is conspicuous within Entine's discussion of the Kalenjin that relegates the cultural effects of their ascetic regimes to a footnote in the foundational physical and physiological explanation of their sporting achievements. As such, the Kalenjin's 'unique cultural factors - altitude, diet, tribal traditions, role model worship, dedicated training' (Entine, 2000a: 64) fail to account for their sporting performance and, instead, are superseded by psychological factors that supple-ment their physiology. Unsurprisingly, citing the impressionistic theories of Fred Hardy and John Velzian,9 Entine argues that these psychological factors are manifested within the infantile innocence that characterizes Kenyan athletic prac-tices that are oriented towards 'enjoyment' and a 'relaxed attitude' in contrast with Western athletes who are consumed by 'ambition'. Therefore, the bio-cultural approach remains rooted in crude biological considerations that are fortified by naturalized and reified cultural assumptions.

\section{'The Subordination of Ethics to Science'}

The above phrase, drawn from the epigraph, demonstrates Tzvetan Todorov's (1993) concern with the deterministic aspects of scientific explanation that vali-dated racialist thought and scientific racism in the late 19th century as objective intellectual pursuits that merely sought to establish the causal factors of racial differentiation. For Todorov, the guiding principle of a predetermined world that might be better understood by the discovery of the laws of nature naturalizes the human world and subsumes the moral sciences. More importantly, the elevation of science at the expense of morality presents a delicate problematic: 'How is the good to be situated with respect to the true?' (Todorov, 1993: 119).

Arguments for the racial basis of athletic propensity are presented as examples of scientific truth that are misunderstood and distorted by ideological dogmas of politically correct notions of social justice. However, an attempt is made to recon-cile this conflict between the scientifically true and the socially good. The often stated interest in fostering open and honest debate on an emotive issue among supporters of the notion of the racial distribution of athletic ability expresses a certain defensive and at times gestural sensitivity to the dangerous social allure and implications of bioculturalism, if not its inescapable and fundamental biologism. In response to a question on his apparent lack of concern that 'pointing to racial differences in physiology opens the door to considering racial differences in intelligence', Entine expresses a concern with this possibility but remarks that it is not a logical conclusion because, unlike athletic ability, intelligence cannot be conclusively measured.10 This allows Entine to use scientific inquiry, intellec-tual freedom and the transparent discussion of issues of human curiosity as grounds to transgress the societal taboo against discussing racial differences. However, rather than facilitating debate, the immense social power of scientific representations and their ability to produce and frame debates on the correlation between race, genetics and athletic ability operate as a form of argumentative closure. 
Published as: St Louis, Brett. 2003. Sport, genetics and the 'natural athlete': The resurgence of racial science. Body \& Society, 9(2), pp. 75-95.

The caricaturing and dismissal of opposing voices as impassioned and irrational sociological and anthropological metapolitical positions diminishes debate and polarizes opinion around a fundamental distinction between the scientific objectification of the concrete and the subjective abstraction of social values. This foreclosure is enhanced by the application of methodological exemp-tions that allow Entine to dismiss critiques that raise the problems arising from extrapolating particular observations into general propositions as demanding an indisputable certainty that create virtually impossible scientific standards. Never-theless, if, as Entine argues, many major scientific theories would remain unproven if they required validation by 'observable evidence or laboratory experiments', we are left to contemplate how necessarily incomplete and disputable scientific knowledge can be mobilized to definitively dismiss valid social questions derived from ethical premises and humanistic concerns.

The hegemonic authority of scientific expertise can also restrict ethical debate through its implicit regulatory aspects. This is evident in the temptation to position Entine and his fellow travellers within scare quotes as 'scientists' involved in 'pseudo-science', or what Hoberman (1997) refers to as 'tabloid science'. As 'scientists' they are opposed to 'proper' scientists/science and their errors can be explained as the mistakes of 'bad' and 'incorrect' science. Scott Fleming's (2001) excellent critique of the thread of racial science within the history of sports science debates on race and sporting performance points out how many such analyses have been un scientific, illogical and biased. However, this position implies the possibility of a truly scientific, logical and impartial analysis of the relationship between genetics, race and athletic ability without specifying the social and ethical responsibilities of such a redemptive project. Therefore, the unregulated disciplinary and social power of science remains; the dismissal of biological determinism as 'bad science' does not eradicate the ethical dangers of a conjectural scientific objectivity that is disseminated and understood within a subjective social world subject to abstract ethical values. In this vein, while recognizing incidences of fraudulent, .awed and falsified experiments, Steven Rose, Leon Kamin and Richard Lewontin's (1984) critique of sociobiology crucially points to the need to distinguish between the actual world of social phenomena' itself and what the social institutions of science have to say about it through the use of scientific methods. scientific descriptions and explanations are thus regarded as deeply embedded within particular social frameworks and the suitability of the questions chosen, explanatory forms, descriptive paradigms and analytical criteria are all historically relative with ethical responsibilities instead of universally absolute and detached from social effects.

The profound ethical implications of the discussion of links between race and sporting ability are obvious in their popular subject, format and dissemination. Writers such as Burfoot and Entine use the genre of popular science to discuss the social phenomenon of sports and reinforce common-sense ideas about innate racial biological differences. This is not to return to the proper/improper or good/bad science dichotomy, but rather illustrates the necessity of sensitivity towards the significance and implications of the position of impressionistic ideas about race within the public domain and popular imagination. A key danger with this public discussion is that it tends to specifically focus on the sporting opera-tionalization of race that limits discussion of its wider ethical implications. Considerations of racial athletic ability draw on the long history, evident for example in the opposition to sporting sanctions against apartheid South Africa and Olympic 
Published as: St Louis, Brett. 2003. Sport, genetics and the 'natural athlete': The resurgence of racial science. Body \& Society, 9(2), pp. 75-95.

boycotts, of the notion that politics and sport ought to be separate as an insulation from rigorous critique. This idealization of sport as an auton-omous site for innocent play amplifies the normative reification of race. The resultant dangers are transparent when publications such as Entine's Taboo (2000a) are placed alongside recent erroneous attempts to use data on genetic vari-ation to verify biological models of racial differences and identify biological races as 'evolutionary monads'. These discussions renew accepted explanations of racial characteristics dating back to the 18th century with the prime objective of reestablishing 'traditional Euro-American race hierarchies of physical and cogni-tive development' (MacEachern, 2000: 359).

\section{New Genetics, Old and New Racisms, and the Enduring Fascination with Racial Difference}

Given the many atrocities committed under the aegis of science, pursuing the scientific basis of sporting ability through the racial distribution of genetic materials entails a series of dilemmas. The unshakable faith in disinterested science as the guardian of enlightened knowledge that opposes the dangers of impressionistic ignorance evades the ethical imperatives necessary for the non-racist standpoint that Entine purports to write from. Perhaps aware of this, Entine recognizes that the controversy surrounding his position is due to the fact that the 'elephant in the living room is intelligence' (2000a: 336) and, as an attempt to resolve this tension, argues that it is 'time to decouple intelligence and physi-cality' (2000a: 337). However, the separation of intelligence and physicality in the context of scientific analyses of race is extremely difficult. Having been inextric-ably linked throughout the history of scientific racism, intelligence and physical-ity are two sides of the same racial science coin and, as demonstrated above, remain firmly connected within contemporary biocultural approaches to the issue of race and natural sporting ability. Furthermore, the spectre of racism does not disappear even with the hypothetical event of the conceptual disentanglement of mind and body. Indeed, it remains deeply problematic to understand IQ as the ethically problematic and socially dangerous frame for the scientific examination of race. This argument posits scientific analyses of race and sport as harmless and eccentric pet theories that have minimal or lesser social effects because of their strict reference to the sporting realm which is 'only' a benign form of recreation and entertainment.

Although we might locate these analyses of race and sport within what Donna Haraway (2000) notes as the broader contemporary 'pseudo-objectivity' of 'genetic fetishism', the motivation and rationale for naturalizing and racializing the sporting body significantly differs from the hyper-modern technological corporealization of the new genetics. Instead, the dangerous symmetry between scientific analyses of racial sporting performance and the contemporary formations of racism is confirmed by the eerie familiarity of the conceptual foun-dations of bioculturalism that are presented as non-racist in their indication of racial differences as opposed to racist assertions of superiority and inferiority. This recognition of innate and irreconcilable difference along ethnic and cultural lines is a key refrain within expressions of what we have come to understand as the 'new racism' (Barker, 1981) or 'cultural racism'. This notion of immutable difference points to the integrity of separate and distinct groups whose cultural and ethnic constitution provides a communicative barrier and has socially degen-erative effects. Additionally, given the appropriation of sport to reinforce popular ideas about biological racial differences buttressed by the 
Published as: St Louis, Brett. 2003. Sport, genetics and the 'natural athlete': The resurgence of racial science. Body \& Society, 9(2), pp. 75-95.

authority of science, biological determinist approaches to race and sport - even in their biocultural guise provide a dangerous and unstated common-sense supplement to the novel cultural racisms of the far, and not-so-far, right.

If, as Marek Kohn notes, '[n]o sport can be assumed to be the sort of culture-free system a scientist would ideally like' (1995: 80), and the genetic codification of racial sporting ability is subject to varied exceptions and inexplicable phenom-ena, a critical question key to the refutation of racial science remains: why does the notion of inherited genetic racial characteristics remain viable and compelling? Crucially, the frontiers opened by the new genetics have engendered moral and ethical debate on ownership, property rights and profit attached to medical research, and foregrounded the relationship between the public and the private spheres, and commercial and individual rights. Similarly, scientific analyses of sport cannot gesture towards its social implications without being committed to engage them fully. It is also perhaps most important to note that a belief in the impartial, concrete truths of objective science does not buy immunity from the subsequent ethical ramifications and responsibilities entailed in pursuing a fundamental fascination with naturalized racial differences. Therefore, even though the notion that social behaviour such as criminality might be pheno-typically measurable and medicalized as criminal congeniality through the prac-tices of phrenology might appear ludicrous to us now, the articulation of race, genetics, and sporting ability and performance retraces much of the same path. In this sense 19th-century racial science does not merely signal naive historical mistakes, but serves as a rehearsal of the articulate racisms of the present that use the simplicity of the common-sense world of sports to animate a reinvigorated scientific racism.

\section{Notes}

I would like to thank Mariam Fraser and John Solomos for their comments on previous drafts of this article. I would also like to thank the anonymous reviewer for their helpful comments.

1. See for example, Canadian Journal of Sport Sciences 13(2), 1988; Index on Censorship 29(4), 2000 and Skeptic 8(1), 2000.

2. Interestingly, Burfoot's article has 'crossed over' from the popular sporting press to academic publication. After its initial 1992 publication in Runner's World magazine, it has been reprinted under the less inflammatory title, 'African Speed, African Endurance' in the collection Anthropology, Sport and Culture (1999) edited by Robert R. Sands.

3. For a discussion of the 'slow-/fast-twitch' paradigm, see Hoberman (1997: 203-6).

4. This raises the significant factor of racial identity being represented within masculinity where the progressive social roles and significance of women's sports and athletic performance is consistently ignored. For detailed discussions of this see Duncan and Messner (1998) and Hargreaves (2000).

5. However, it is widely recognized that the racialized constancy of genes is difficult to isolate: 'Human beings possess a far larger proportion of genes in common than they do genes that are supposed to differentiate them racially' (Goldberg, 1993: 67).

6. 'Door Opens on Deeper Mysteries', Guardian, 12 February 2001: 6. 
Published as: St Louis, Brett. 2003. Sport, genetics and the 'natural athlete': The resurgence of racial science. Body \& Society, 9(2), pp. 75-95.

7. http://www.celera.com/genomics/news/articles/02_01/Whose_genome.cfm: 29 March 2001.

8. It is worth noting that this does not necessarily suggest the reduction of the body to a prior cognitive apparatus. For example lan Burkitt (1999) argues that individual experience, perception and identity emerge from sensory embodiment allied with its cultural mediation.

9. Fred Hardy is a retired US college track coach who consistently recruited Kalenjin athletes and John Velzian is a Kenyan coach.

10. D.W. Miller, 'Interview with Jon Entine', Chronicle of Higher Education, 31 March 2000: A26.

\section{References}

Bale, John (1999) 'Kenyan Runners in a Global System', pp. 73-95 in R.R. Sands (ed.) Anthropology, Sport, and Culture. Westport, CT: Bergin and Garvey.

Barker, Martin (1981) The New Racism. London: Junction Books.

Benedict, Ruth (1935) Patterns of Culture. London: Routledge and Kegan Paul.

Blake, Andrew (1996) The Body Language: The Meaning of Modern Sport. London: Lawrence and Wishart.

Bouchard, Claude (1988) 'Genetic Basis of Racial Differences', Canadian Journal of Sport Sciences 13(2): 104-8.

Boulay, Marcel R., Pierre F.M. Ama and Claude Bouchard (1988) 'Racial Variation in Work Capaci-ties and Powers', Canadian Journal of Sport Sciences 13(2): 127-35.

Bourdieu, Pierre (1990) 'Programme for the Sociology of Sports', pp. 156-67 in In Other Words: Essays Towards a Reflexive Sociology. Cambridge: Polity.

Bourdieu, Pierre (1992) 'How Can One be a Sports Fan?', pp. 339-55 in S. During (ed.) The Cultural Studies Reader. London: Routledge.

Brohm, Jean-Marie (1978) Sport, A Prison of Measured Time: Essays. London: Ink Links.

Burfoot, Amby (1992) 'White Men Can't Run', Runner's World August: 89-95.

Burfoot, Amby (1999) 'African Speed, African Endurance', pp. 53-63 in R.R. Sands (ed.) Anthro-pology, Sport, and Culture. Westport, CT: Bergin and Garvey.

Burkitt, Ian (1999) Bodies of Thought: Embodiment, Identity and Modernity. London: Sage. 
Published as: St Louis, Brett. 2003. Sport, genetics and the 'natural athlete': The resurgence of racial science. Body \& Society, 9(2), pp. 75-95.

Carrington, Ben and Ian McDonald (2001) 'Introduction: "Race", Sport and British Society', pp. 1-26 in B. Carrington and I. McDonald (eds) 'Race', Sport and British Society. London: Routledge.

Cashmore, Ellis E. (1982) Black Sportsmen and Society. London: Routledge and Kegan Paul.

Cuvier, Georges Léopold (1997) 'Varieties of the Human Species', pp. 104-8 in E.C. Eze (ed.) Race and the Enlightenment: A Reader. Oxford: Blackwell.

Dennis, Carina, Richard Gallagher and Phillip Campbell (2001) 'Everyone's Genome', Nature 409 (15 Feb.): 813.

Duncan, Margaret Carlisle and Michael A. Messner (1998) 'The Media Image of Sport and Gender', pp. 170-85 in Lawrence A. Wenner (ed.) MediaSport. London: Routledge.

Dyreson, Mark (1989) 'Melting-pot Victories: Racial Ideas and the Olympic Games in American Culture during the Progressive Era', International Journal of the History of Sport 6(1): 49-61.

Edwards, Harry (1973) The Sociology of Sport. Homewood, IL: Dorsey Press.

Entine, Jon (2000a) Taboo: Why Black Athletes Dominate Sports and Why We're Afraid to Talk About It. New York: Public Affairs.

Entine, Jon (2000b) 'Breaking the Taboo', Index on Censorship 29(4): 62-4.

Feyerabend, Paul (1978) Science in a Free Society. London: New Left Books.

Fleming, Scott (2001) 'Racial Science and South Asian and Black Physicality’, pp. 105-20 in B. Carring-

ton and I. McDonald (eds) 'Race', Sport and British Society. London: Routledge. Gilroy, Paul (2000) Between Camps: Nations, Cultures and the Allure of Race. London: Allen

Lane/Penguin Press.

Gobineau, Arthur de (1966) The Inequality of Human Races. Los Angeles, CA: Noontide Press.

Goldberg, David Theo (1993) Racist Culture: Philosophy and the Politics of Meaning. Oxford: Blackwell.

Gould, Stephen Jay (1997) The Mismeasure of Man, revised and expanded edn. Harmondsworth: Penguin. 
Published as: St Louis, Brett. 2003. Sport, genetics and the 'natural athlete': The resurgence of racial science. Body \& Society, 9(2), pp. 75-95.

Guillaumin, Collette (1995) Racism, Sexism, Power and Ideology. London: Routledge.

Haraway, Donna (2000) 'Deanimations: Maps and Portraits of Life Itself', pp. 111-36 in A.E. Coombes and A. Brah (eds) Hybridity and its Discontents: Politics, Science, Culture. London: Routledge.

Hargreaves, Jennifer (ed.) (1982) Sport, Culture and Ideology. London: Routledge and Kegan Paul.

Hargreaves, Jennifer (2000) Heroines of Sport: The Politics of Difference and Identity. London: Routledge.

Hargreaves, John (1986) Sport, Power and Culture: A Social and Historical Analysis of Popular Sports in Britain. Cambridge: Polity.

Hegel, G.W.F. (1975) Lectures on the Philosophy of World History: Introduction, Reason in History. Cambridge: Cambridge University Press.

Herrnstein, Richard J. and Charles Murray (1996) The Bell Curve: Intelligence and Class Structure in American Life. London: Simon and Schuster.

Hoberman, John (1997) Darwin's Athletes: How Sport has Damaged Black America and Preserved the Myth of Race. New York: Houghton.

International Human Genome Sequencing Consortium (2001) 'Initial Sequencing and Analysis of the Human Genome', Nature 409(15 Feb.): 860-921.

Jones, Steve (1994) The Language of the Genes: Biology, History and the Evolutionary Future. London: HarperCollins.

Knox, Robert (1996) 'Extract from The Races of Men', pp. 240-60 in H.F. Augstein (ed.) Race: The Origins of an Idea, 1760-1850. Bristol: Thoemmes Press.

Kohn, Marek (1995) The Race Gallery: The Return of Racial Science. London: Jonathan Cape.

Kuhn, Thomas (1970) The Structure of scientific Revolutions, 2nd edn. Chicago, IL: University of Chicago Press.

Locke, John (1960) Two Treatises of Government. Cambridge: Cambridge University Press. 
Published as: St Louis, Brett. 2003. Sport, genetics and the 'natural athlete': The resurgence of racial science. Body \& Society, 9(2), pp. 75-95.

MacEachern, Scott (2000) 'Genes, Tribes, and African History', Current Anthropology 41(3): 357-84.

Maguire, Joseph (1999) Global Sport: Identities, Societies, Civilizations. Cambridge: Polity.

Malina, Robert M. (1988) 'Racial/Ethnic Variation in the Motor Development and Performance of American Children', Canadian Journal of Sports Sciences 13(2): 136-43.

Miles, Robert (1989) Racism. London: Routledge.

Monaco, James (2000) How to Read a Film: Movies, Media, Multimedia, 3rd edn. Oxford: Oxford

University Press. Popper, Karl (1963) Conjectures and Refutations: The Growth of scientific Knowledge. London:

Routledge and Kegan Paul.

Rose, Steven (1997) Lifelines: Biology, Freedom, Determinism. Harmondsworth: Penguin.

Rose, Steven, Leon J. Kamin and Richard C. Lewontin (1984) Not in Our Genes: Biology, Ideology and Human Nature. Harmondsworth: Penguin.

Sahlins, Marshall (1977) The Use and Abuse of Biology: An Anthropological Critique of Sociobiology. London: Tavistock.

Samson, Jacques and Magdeleine Yerlès (1988) 'Racial Differences in Sports Performance', Canadian Journal of Sport Sciences 13(2): 109-16.

Sands, R.R. (ed.) (1999) Anthropology, Sport, and Culture. Westport, CT: Bergin and Garvey.

Todorov, Tzvetan (1993) On Human Diversity: Nationalism, Racism, and Exoticism in French Thought. Cambridge, MA: Harvard University Press.

Venter, J. Craig et al. (2001) 'The Sequence of the Human Genome’, Science 291(16 Feb.): 1304-51.

Wade, Peter (1993) ' "Race”, Nature and Culture', Man (N.S.) 28: 17-34.

Brett St Louis is Lecturer in Sociology at the University of Bristol. 
Published as: St Louis, Brett. 2003. Sport, genetics and the 'natural athlete': The resurgence of racial science. Body \& Society, 9(2), pp. 75-95. 